This item was submitted to Loughborough's Research Repository by the author.

Items in Figshare are protected by copyright, with all rights reserved, unless otherwise indicated.

\title{
The effect of applied electric field on pulsed radio frequency and pulsed direct current plasma jet array
}

PLEASE CITE THE PUBLISHED VERSION

http://dx.doi.org/10.1063/1.4729730

PUBLISHER

(C) American Institute of Physics

VERSION

VoR (Version of Record)

LICENCE

CC BY-NC-ND 4.0

REPOSITORY RECORD

Hu, J.T., X.Y. Liu, J.H. Liu, Z.L. Xiong, D.W. Liu, X.P. Lu, Felipe Iza, and Michael G. Kong. 2019. "The Effect of Applied Electric Field on Pulsed Radio Frequency and Pulsed Direct Current Plasma Jet Array”. figshare. https://hdl.handle.net/2134/16398. 


\section{AIP $\left.\right|_{\text {Physics of }}$ \\ Plasmas}

The effect of applied electric field on pulsed radio frequency and pulsed direct current plasma jet array

J. T. Hu, X. Y. Liu, J. H. Liu, Z. L. Xiong, D. W. Liu, X. P. Lu, F. Iza, and M. G. Kong

Citation: Physics of Plasmas (1994-present) 19, 063505 (2012); doi: 10.1063/1.4729730

View online: http://dx.doi.org/10.1063/1.4729730

View Table of Contents: http://scitation.aip.org/content/aip/journal/pop/19/6?ver=pdfcov

Published by the AIP Publishing

Articles you may be interested in

Characteristics of a Direct Current-driven plasma jet operated in open air

Appl. Phys. Lett. 103, 144107 (2013); 10.1063/1.4824305

Modeling of helium plasma jets emerged into ambient air: Influence of applied voltage, jet radius, and helium flow velocity on plasma jet characteristics

J. Appl. Phys. 112, 103304 (2012); 10.1063/1.4766297

The driving frequency effects on the atmospheric pressure corona jet plasmas from low frequency to radio frequency

Phys. Plasmas 18, 043503 (2011); 10.1063/1.3574256

Electric probe investigations of microwave generated, atmospheric pressure, plasma jets

J. Appl. Phys. 108, 013301 (2010); 10.1063/1.3448034

Characteristics of electromagnetically accelerated plasma flow in an externally applied magnetic field

Phys. Plasmas 14, 093507 (2007); 10.1063/1.2773701

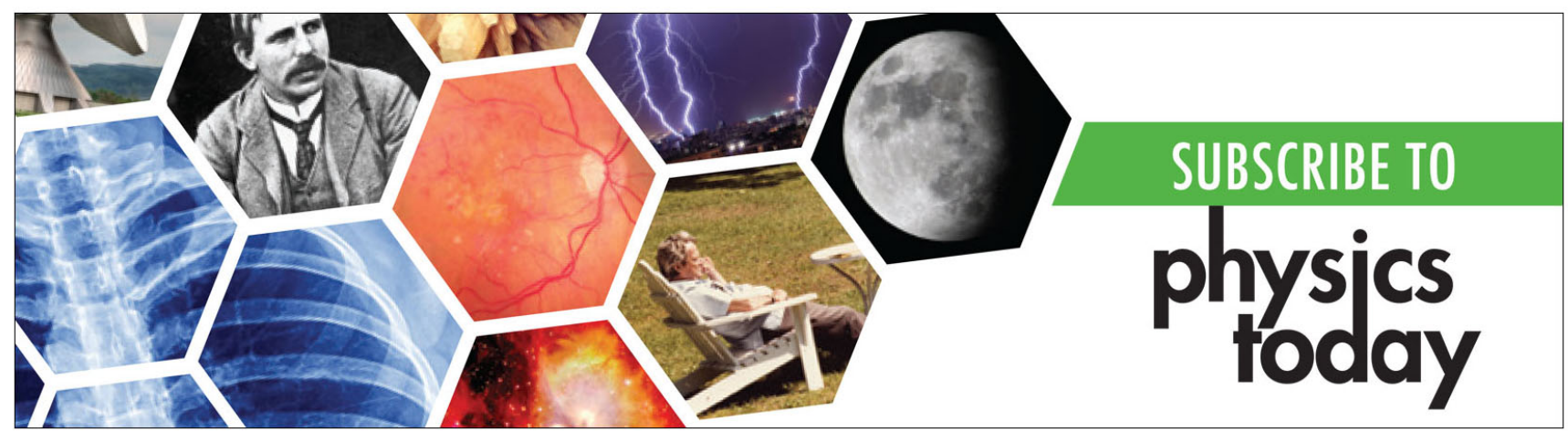




\title{
The effect of applied electric field on pulsed radio frequency and pulsed direct current plasma jet array
}

\author{
J. T. Hu, ${ }^{1}$ X. Y. Liu, ${ }^{1}$ J. H. Liu, ${ }^{1}$ Z. L. Xiong, ${ }^{1}$ D. W. Liu,${ }^{1}$ a) X. P. Lu, ${ }^{1}$ F. Iza, ${ }^{2}$ and M. G. Kong ${ }^{2}$ \\ ${ }^{1}$ National State Key Lab of Advanced Electromagnetic Engineering and Technology, Huazhong University \\ of Science and Technology, WuHan, Hubei 430074, People's Republic of China \\ ${ }^{2}$ Department of Electronic and Electrical Engineering, Loughborough University, Leicestershire LE11 3TU, \\ United Kingdom
}

(Received 13 February 2012; accepted 18 May 2012; published online 18 June 2012)

\begin{abstract}
Here we compare the plasma plume propagation characteristics of a 3-channel pulsed RF plasma jet array and those of the same device operated by a pulsed dc source. For the pulsed-RF jet array, numerous long life time ions and metastables accumulated in the plasma channel make the plasma plume respond quickly to applied electric field. Its structure similar as "plasma bullet" is an anode glow indeed. For the pulsed dc plasma jet array, the strong electric field in the vicinity of the tube is the reason for the growing plasma bullet in the launching period. The repulsive forces between the growing plasma bullets result in the divergence of the pulsed dc plasma jet array. Finally, the comparison of $309 \mathrm{~nm}$ and $777 \mathrm{~nm}$ emissions between these two jet arrays suggests the high chemical activity of pulsed RF plasma jet array. (C) 2012 American Institute of Physics.

[http://dx.doi.org/10.1063/1.4729730]
\end{abstract}

\section{INTRODUCTION}

Nowadays biomedical application of atmospheric pressure glow discharges (APGDs) known as plasma medicine has received growing attention due to their economic and technological impact. ${ }^{1,2}$ The plasma jet plays a key role in the biomedical application because of its capability to provide plasmas not spatially bound or confined by electrodes. ${ }^{3}$ The plasma jet driven by $\mathrm{kHz}$ high voltage ac source was first used to fulfill the sterilization purpose. ${ }^{4}$ Pulsed dc plasma jet is popular in plasma medicine due to its advantage of long plasma plume and low gas temperature. ${ }^{5,6}$ Although the RF plasma jet has much higher density of reactive species, ${ }^{7-9}$ the gas temperature of hundreds degrees is too hot to the biomedical application. The pulsed RF plasma jet decreases the gas temperature to room temperature through limiting power on duty cycle. ${ }^{10,11}$ In this paper, we present experiment data at revealing the effect of applied electric field on plasma plume propagation of pulsed RF jet array and pulsed dc jet array. The chemical reactivity of these two plasma jet arrays are also compared.

\section{EXPERIMENT SETUP}

The plasma jet array used for this study employed three dielectric tubes of $5 \mathrm{~cm}$ long, one end of which was wrapped with a concentric tin belt of $2 \mathrm{~cm}$ wide. This tin belt served as the powered electrode. As shown in Fig. 1, both ends of the glass tubes were opened so that the plasma working gas (helium) flew into these three glass tubes from the injection ports at $5 \mathrm{slm}$ (standard liter pre minute), and the plasma flushed out of the generator from the outlet on the other end.

A function generator (Tektronix AFG3021B), a rf power amplifier (Ruisijieer RSG-K), and a homemade matching net-

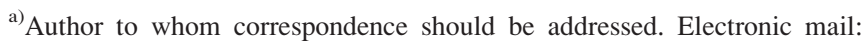
liudw@hust.edu.cn.
}

work are used to deliver the pulsed rf power to the power electrode. A dc high voltage power supply (SL150KV), a high voltage pulse generator (PVX-1440), and the same function generator are used to deliver the pulsed dc power to the electrode. The voltages and currents were measured using a Tektronix P6015 voltage probe and a Tektronix TCP202 current probe, respectively. The signals collected by the probes were recorded by a digital Tektronix DPO7104 oscilloscope. An intensified charge coupled device (ICCD) camera (Princeton Instruments, PIMAX2) was used to capture the dynamics of the plasma plumes. For the high-speed imaging, the exposure time of the ICCD camera was set at $5 \mathrm{~ns}$. Optical filters (Thorlabs full width at half maximum $10 \mathrm{~nm}$ ) were used to take wavelength resolved images The optical emission spectra (OES) of the plasma plumes were measured by a half meter spectrometer (Princeton Instruments Acton SpectraHub 2500i), and the grating and the slit width of the spectrometer were set at 1200 groove $/ \mathrm{mm}$ and $200 \mu \mathrm{m}$.

The pulse frequency of the pulsed dc plasma and pulsed RF plasma both were $4 \mathrm{kHz}$. The RF of the pulsed RF plasma was $12.5 \mathrm{MHz}$, and its power on duty cycle was $1.28 \%$ (40 RF cycles), which was $3.2 \mu$ s and equal to the power on period of the pulsed dc plasma. The maximum peak-to-peak RF voltage was $9 \mathrm{kV}$ (Fig. 2(a)), and the pulsed dc voltage was $6.4 \mathrm{kV}$ (RMS value of the max pk-pk RF voltage, Fig. 2(b)).

\section{RESULTS AND DISCUSSION}

\section{A. The rf electric field effect on plasma plume propagation}

The inserted picture in Fig. 2(a) shows the plasma plume length of pulsed RF jet array approaches $1.3 \mathrm{~cm}$. Because the different stray capacitance of the array structure and its different effective impedance in the external structure, the bottom plume is more active. Figs. 3(a)-3(d) show the propagation dynamics of the pulsed RF jet array. In the positive half rf 


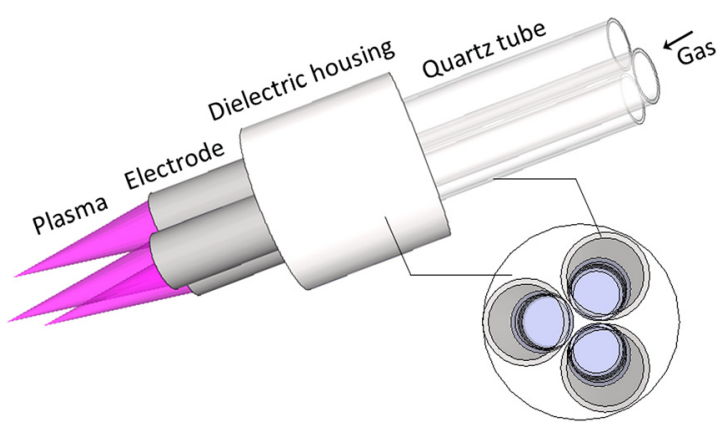

FIG. 1. Schematic of the 3 tubes plasma jet array.

cycle started at $2658 \mathrm{~ns}$, the plasma first appears as a positive corona with a length $<0.1 \mathrm{~cm}$ (not shown, peak RF voltage $=3 \mathrm{kV}$ ), which is same as the observation in Ref. 10 . 4 RF cycles later, the length of plasma plume was $0.25 \mathrm{~cm}$ (peak RF voltage $=3.7 \mathrm{kV}$, Fig. 3(a)). Afterwards, the length of plasma plume increased to $1.3 \mathrm{~cm}$ at the maximum peak voltage of $4.4 \mathrm{kV}$ (Fig. 3(c)). This is a $5 \times$ increase in length over $1.2 \times$ applied voltage increase. The average plasma plume propagation velocity is $2.73 \times 10^{6} \mathrm{~cm} / \mathrm{s}$.

The plasma plume structure changed during its propagation. Although the structure similar to the plasma bullet arose at the negative voltage peak of $-4 \mathrm{kV}$ (Fig. 3(b)), the plasma image (Fig. 3(c)) taken at the following negative RF voltage peak suggests the plasma plume was dominated by the positive column. In order to study the development of the pulsed rf plasma plume, the propagation dynamics during one rf cycle was shown in Fig. 4. The applied RF voltage amplitude decreased to 0 at a quarter cycle after Fig. 3(c), therefore only accumulated charges on the dielectric tube surface can maintain the electric field and the ionization and excitation in the plume, which led to the weaker optical emission intensity of plumes (Fig. 4(a)). Because the numerous long lifetime (compared with RF cycle in ns scale) ions and metastables ${ }^{14}$ accumulated in the channel made the whole plasma plume responded quickly to the applied RF voltage, the structure of stable glow discharge is used to analyze the pulsed RF plasma plume as Ref. 15. Fig. 4(b) shows the structure of negative glow, Faraday dark space and positive column from the plasma plume tip to electrodes at the positive rf voltage peak. Different from secondary electrons produced by ion bombardment on electrode, ${ }^{16}$ the photoionization ${ }^{12,13}$ near the plasma
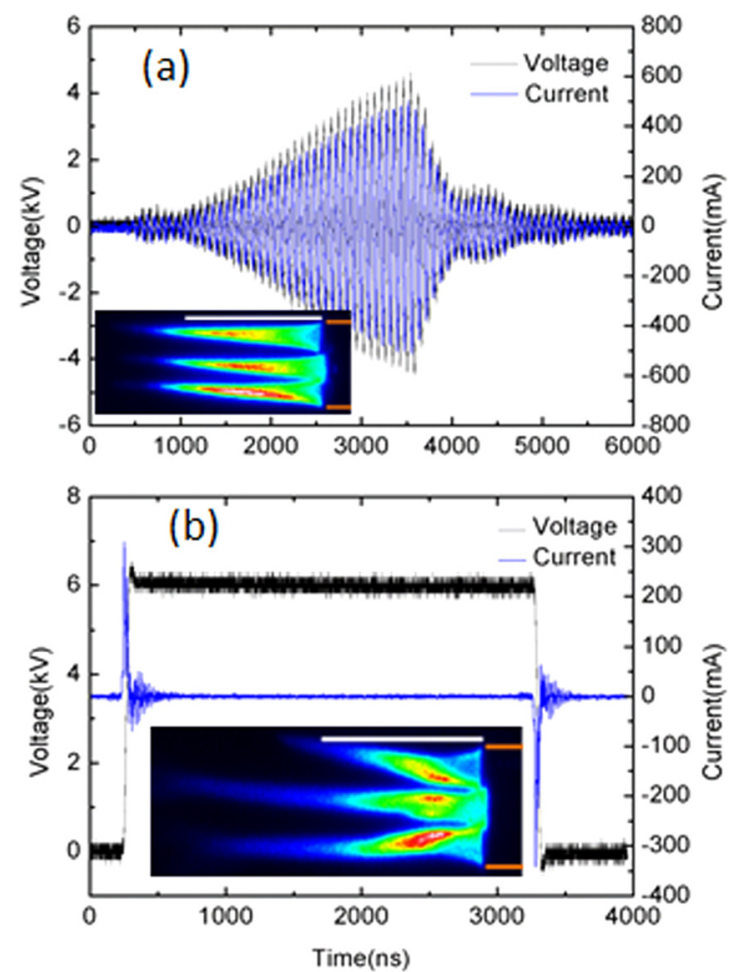

FIG. 2. (a) Current and voltage characteristics (CVC) of pulsed RF plasma jet array in one pulse cycle. The inserted picture is taken with $10 \mathrm{~ms}$ exposure time, and the brown line shows the tube exit position, white line in the top shows the length of $1 \mathrm{~cm}$. (b) CVC of pulsed dc jet array. The inserted picture has the same condition as the top one.

tip can only provide much less seed electrons, therefore the negative glow in the plume head was weaker than that near the ground electrode in Ref. 15. These seed electrons were then accelerated towards the tube and intensified the discharge in the main body of plasma plume. Finally, this energetic electron stream reached the tube which worked as a hollow anode. ${ }^{16}$ The higher helium concentration intensified the discharge inside the tube furthermore. Consequently, more applied power are consumed by discharge inside the tube in the positive half cycle, and the comparison between Figs. 4(b) and 4(d) also indicates that the emission intensity of plasma plume outside the tube was weaker at the positive voltage peak than that at the negative voltage peak. On the other hand, because electrons accumulated on the surface of the dielectric tube, a strong electric field formed between the
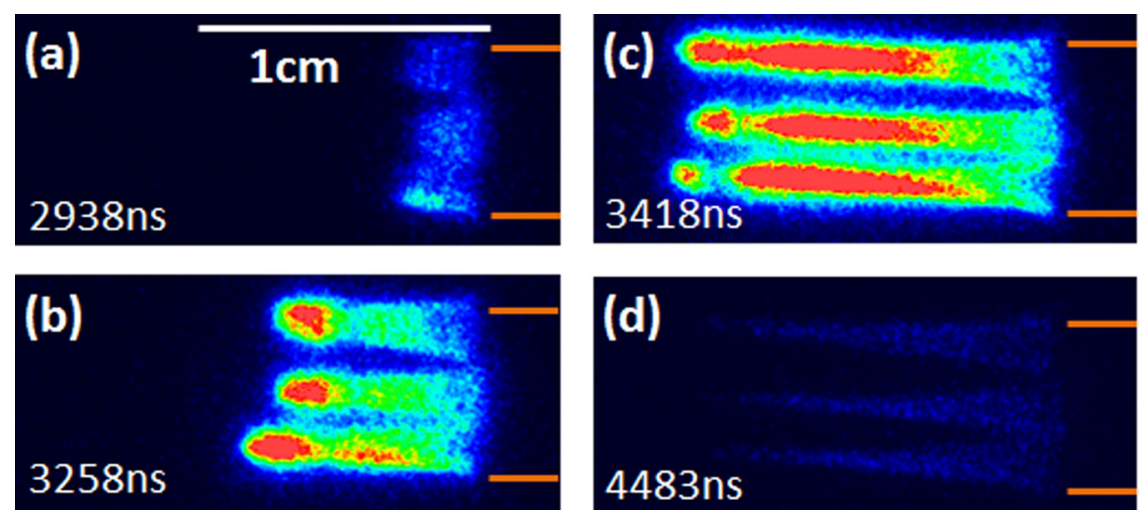

FIG. 3. The pulsed RF jet array development in the pulse on and pulse off periods. Each image was taken with $5 \mathrm{~ns}$ exposure time. The starting time of each image is with reference to Fig. 1(a). 

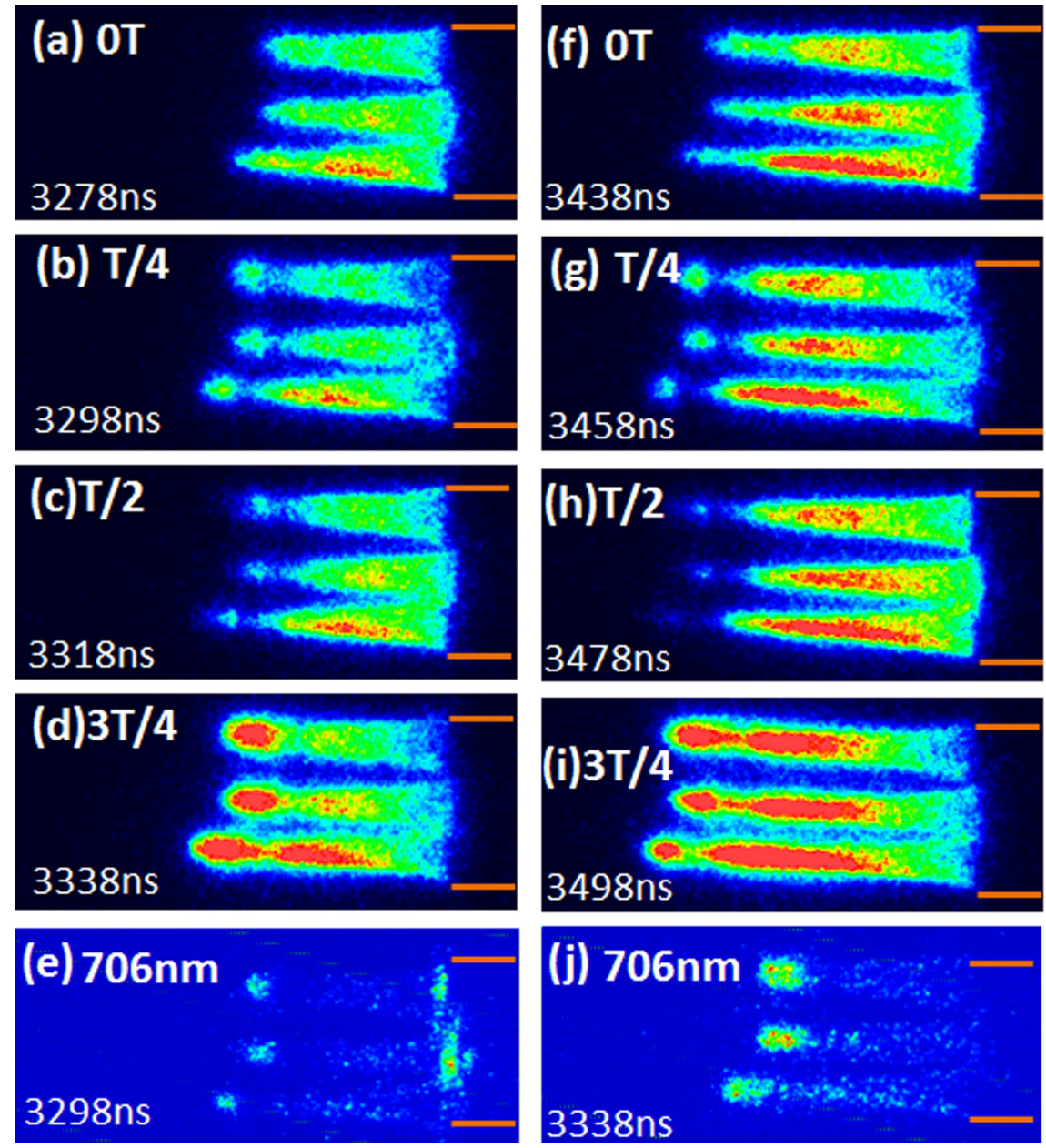

FIG. 4. The pulsed RF jet array dynamics in two rf cycles during pulse on period. Each image was taken with $5 \mathrm{~ns}$ exposure time. [(a)-(d) and (f)-(i)] wavelength-integrated, (e) and (j) $706 \mathrm{~nm}$. surface and the tin belt electrode, which is captured by the strong $706 \mathrm{~nm}$ emission ${ }^{17}$ near the tube exit [Fig. 3(e)].

In the negative half cycle, besides the stronger emission intensity, the plasma plume structure is different from that in the positive half cycle [compare Figs. 4(b) and 4(d)]. The middle plasma plume in Fig. 4(d) shows the structure of anode glow, anode dark space, and positive column from the plasma plume head to the tube exit. Because of much smaller mobility than electrons, ${ }^{16}$ the number of positive ions reached the dielectric tube and accumulated was less than electrons in the positive half cycle, and the field concentration near the electrode is not observed in the negative half cycle [compare Figs. 4(e) and 4(j)]. The discharge inside the tube is a hollow cathode discharge indeed. Electrons converged to the axis and flushed out of the tube. ${ }^{16}$ This energetic electron stream not only intensified the ionization and excitation in the positive column, but also propagated further along the plasma channel. Consequently, as the rf voltage amplitude increased, besides the brighter positive column plume, the length of plasma plumes in Fig. 4(d) is longer than that in Fig. 3(b) at the previous negative voltage peak. The electron stream finally stopped in the plume head and formed a block of high density negative space charge. ${ }^{16}$ The emission pattern at $706 \mathrm{~nm}$ (Fig. 4(j)) captured the strong electric field in this region due to the high density negative charge. More ionization and excitation reactions happened in this region led to the formation of the structure similar to plasma bullet (Figs. 4(d) and 3(b)). This strong electric field is also an obstruction for the electron stream, and part of the electron stream could not get through it, so the anode dark space arose between the anode glow and the positive column in the top and middle plasma plume in Fig. 4(d).

The rf plasma jet array propagation dynamics at two $\mathrm{rf}$ cycles after Fig. 4(a) are shown in Figs. 4(e)-4(h). The comparison between Figs. 4(a)-4(d) and Figs. 4(e)-4(h) indicates the same structure of plasma plumes from cycle to cycle. The only $3 \%$ increment of the applied voltage amplitude from $4.14 \mathrm{kV}$ to $4.26 \mathrm{kV}$, not only increased the plasma plume length from $0.9 \mathrm{~cm}$ to $1.2 \mathrm{~cm}$ but also intensified discharge. After the maximum rf voltage amplitude at $3418 \mathrm{~ns}$, the length of plasma plume did not decrease as fast as the applied voltage, and the length was still $1.3 \mathrm{~cm}$ even at the applied rf peak voltage of only $1.1 \mathrm{kV}$ (Fig. 3(d)). The fast increasing plasma plume during the pulse on period and the slowly decaying plasma plume afterwards were all attributed to the plasma channel maintained by the long life time ions and metastables. ${ }^{14,18}$ The plasma plume disappeared at $5000 \mathrm{~ns}$ in the end, so the total plasma working time is $2342 \mathrm{~ns}$.

\section{B. The growing plasma bullet and the divergent pulsed dc plasma jet array}

The inserted picture in Fig. 2(b) shows the pulsed dc jet array with a length of approaching $2 \mathrm{~cm}$, whose bottom plume 

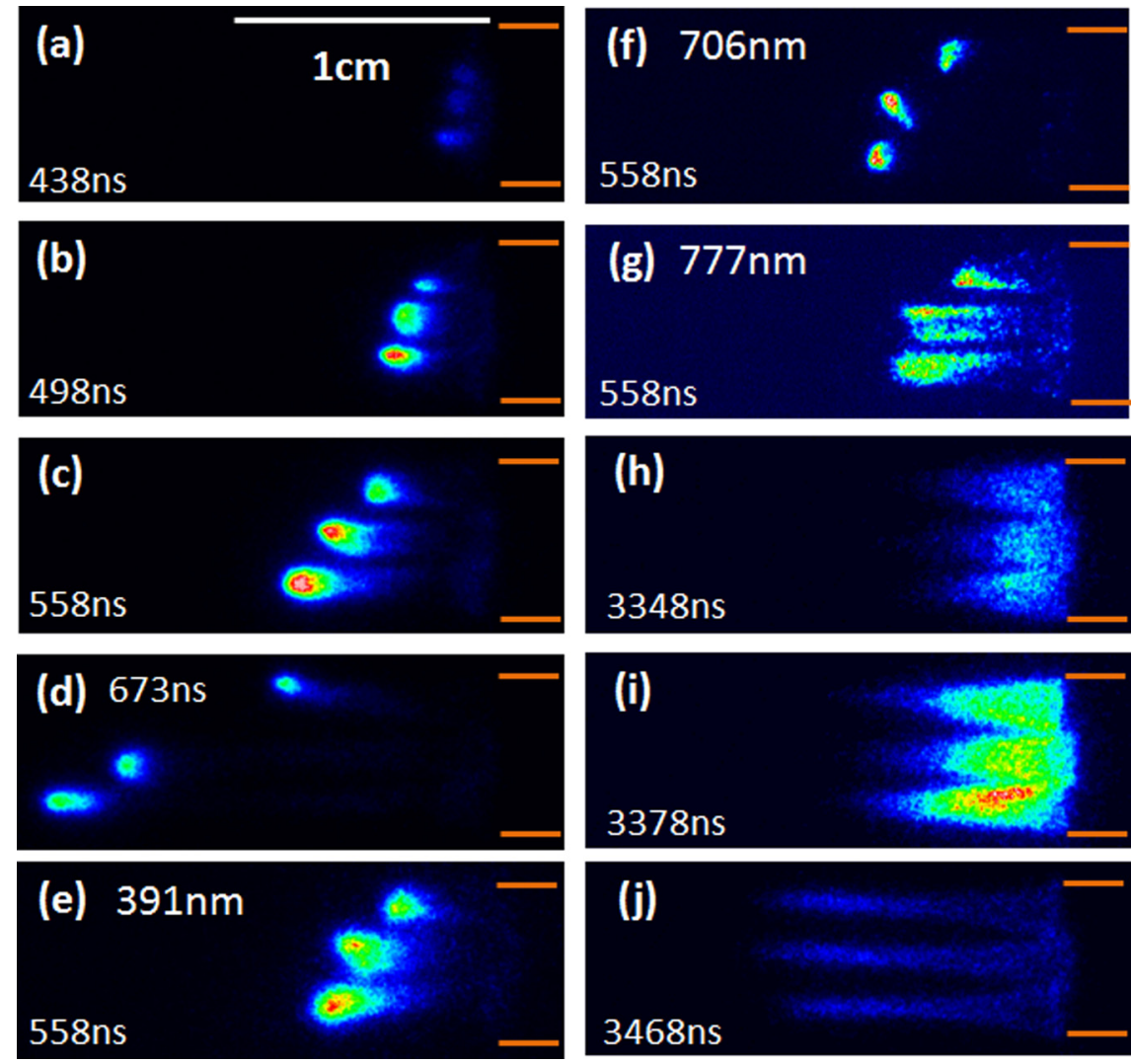

FIG. 5. The pulsed dc jet array dynamics in the pulse rising and falling phase. Each image was taken with $5 \mathrm{~ns}$ exposure time. [(a)-(d) and (h)-(j)] wavelength-integrated, (e) $391 \mathrm{~nm}$, (f) $706 \mathrm{~nm}$, and (g) $777 \mathrm{~nm}$. was also stronger. Figs. 5(a)-5(d) show the plasma plume propagation dynamics of pulsed jet array. The plasma bullet reached the maximum velocity of $7.5 \times 10^{6} \mathrm{~cm} / \mathrm{s}$ (Fig. $5(\mathrm{c})$ ) in the launching period, afterwards the bullet turned weaker in the propagating period (Fig. 5(d)). ${ }^{19}$ Although Dawnson's theorem basing on zero applied electric field is highly plausible to explain the formation of plasma bullet, ${ }^{3,12}$ the plasma bullet propagation dynamics shown in Fig. 5 suggests the applied electric field played a key role in the plasma propagation. During the launching period, not only the radius of the plasma bullet increased from $0.045 \mathrm{~cm}$ (Fig. 5 (b)) to $0.07 \mathrm{~cm}$ (Fig. 5(c)) but also the bullet was brighter. Because the all wavelength emission has the same pattern as the $391 \mathrm{~nm}$ emission $^{17}$ $\left(N_{2}^{+}\left(B^{2} \Sigma_{g}^{+}\right) \rightarrow N_{2}^{+}\left(X^{2} \Sigma_{g}^{+}\right)+h \lambda\right.$, compare Figs. 5(c) and $5(\mathrm{e}))$, the brighter bullet suggests the increasing ion density in the launching period. This growing radius and positive ion density in the launching period were not considered in Dawnson's theorem. ${ }^{12}$ Additionally, this growing plasma bullet (Fig. 5(c)) and the shrinking plasma bullet in the propagating period (Fig. 5(d)) support the theoretical prediction in Ref. 20 that the ion density in the streamer tip increased in the high field region and then dropped until the streamer propagation stopped. According to the photon-ionization theory, the photo electrons created in a distance from the bullet tip were accelerated towards the bullet filled with positive ions. Besides the electric field of bullet its own, the highly stressed applied electric field ${ }^{20}$ and the lower air mole fraction ${ }^{21}$ in the vicinity of the tube not only facilitated the energy coupled to this electron stream $\varepsilon=E \times j_{e}$ (E is the applied electric field, $j_{e}$ is the electron flux $)^{16}$ but also intensified the excitation and ionization; therefore, the growing plasma bullet in the launching period was only near to the tube exit. After that, as the bullet moved further in the propagating period, the energy coupled from the weaker applied electric field decreased, but the energy consumed more quickly by higher air mole fraction, so the bullet turned weaker until disappeared in the end.

The inserted picture in Fig. 2(b) also suggests that different from the parallel plasma plume of the pulsed rf jet array [insert in Fig. 2(a)], the plasma plumes of pulsed dc plasma jet array were divergent, especially in the region less than $1 \mathrm{~cm}$ from the tube exit. In this region, the plasma plume propagation dynamics shows the vertical gap between the middle and the bottom plasma bullet increased from $0.04 \mathrm{~cm}$ [Fig. 5(b)] to $0.09 \mathrm{~cm}$ [Fig. 5(c)], and the width of the plasma jet array also increased from $0.37 \mathrm{~cm}$ to $0.56 \mathrm{~cm}$. This is attributed to increasing repulsive forces between the growing plasma bullet filled with positive ions. ${ }^{14,19}$ The similar divergent plasma bulbs were also observed in the long gas gap streamer discharge. ${ }^{16}$ In terms of the pulsed RF jet array, because the positive column dominated the plasma plume and its electric neutrality ${ }^{15}$ made the repulsive force between the plasma channel negligible, plasma plumes were parallel [Figs. 3 and 4].

The $706 \mathrm{~nm}$ emission shown in Fig. 5(f) indicates the field concentration in front of the bullet. This is caused by photo electrons and positive ions left by previous photonionization, and also support the theoretical prediction regarding the peak axil electric field of the plasma bullet at the same position. ${ }^{15}$ The weak space dependence $777 \mathrm{~nm}$ emission $\left(\mathrm{O}\left({ }^{5} \mathrm{p}_{1}\right) \rightarrow \mathrm{O}\left({ }^{5} \mathrm{~s}_{2}\right)+\mathrm{h} \lambda\right.$, Fig. $\left.5(\mathrm{~g})\right)$ indicates that $\mathrm{O}\left({ }^{5} \mathrm{P}_{1}\right)$ is mainly produced by collisions with long lived metastabels. ${ }^{17,22}$ At the end of the pulse voltage, the 


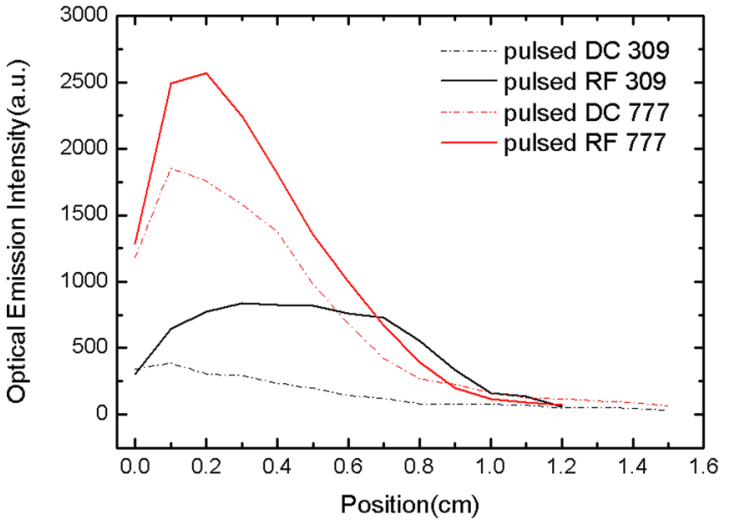

FIG. 6. Optical emission intensity at $309 \mathrm{~nm}$ and $777 \mathrm{~nm}$ along the plasma plume of pulsed RF and pulsed dc plasma jet array.

secondary discharge propagated along the ionization channel as Figs. 5(h) $-5(\mathrm{j})$, which is attributed to the accumulated electrons released from the tube surface, and the electron flux along the channel is in the opposite direction to the bullet mode. The plasma working time including the secondary discharge is $1700 \mathrm{~ns}$.

\section{The comparison between the pulsed RF and pulsed dc plasma jet array}

The averaged propagation velocity of the pulsed $\mathrm{dc}$ plasma is $6.1 \times 10^{6} \mathrm{~cm} / \mathrm{s}$, more than twice of pulsed RF plasma velocity. Although the pulsed dc plasma plume is longer than the pulsed RF plasma plume, the insert in Figs. 2(a) and 2(b) suggests the active zone of the two plasma plumes has the similar length $(\approx 1 \mathrm{~cm})$. By putting the optic fiber at the distance of $2 \mathrm{~cm}$ from the centre tube and moving along the plasma plume propagating direction, the optical emission intensity as a function of plasma plume position is obtained and shown in Fig. 6. The higher emission intensity at $309 \mathrm{~nm}\left(\mathrm{OH}\left(A^{2} \Sigma(v=0)\right) \rightarrow O H\left(X^{2} \Sigma(v=0)\right)+h \lambda\right)$ and $777 \mathrm{~nm}$ indicates the higher concentration of $\mathrm{OH}$ radicals and atomic oxygen in the active plume zone of the pulsed RF plasma jet array, which is attributed to the intensified discharge along the channel under fast oscillating RF electric field and longer plasma working time.

\section{CONCLUSION}

In conclusion, the effect of the applied electric field on different plasma jet array has been analyzed. For the pulsed RF jet array, due to the ions and metastables with long life- time accumulated in the channel, the energetic electron stream accelerated by the fast oscillating RF electric field made the RF plasma plume has the same structure as stable glow discharge. For the pulsed dc plasma plume, the growing plasma bullet which cannot be explained by Dawson theory is actually attributed to the high electric field in the vicinity of the electrode through coupling power to electron stream towards the electrode. Different from the parallel plasma plumes of the pulsed RF jet array, the repulsive force caused by the high concentration positive ions in the growing bullets lead to the divergent pulsed dc plasma jet array. Finally, the comparison of the OES suggested the high chemical reactivity of the pulsed RF plasma plume.

\section{ACKNOWLEDGMENTS}

This work was supported by the National Natural Science Foundation of China under Grant No. 51007029, Foundation from HUST under Grant No. 2012QN197 and the SRF for ROCS, SEM.

${ }^{1}$ D. Dobrynin, G. Fridman, G. Friedman, and A. Fridman, New J. Phys. 11, 115020 (2009).

${ }^{2}$ M. G. Kong, G. Kroesen, G. Morfill, T. Nosenko, T. Shimizu, J. van Dijk, and J. L. Zimmermann, New J. Phys. 11, 115012 (2009).

${ }^{3}$ M. Laroussi and T. Akan, Plasma Processes Polym. 4, 777-788 (2007).

${ }^{4}$ M. Laroussi, IEEE Trans. Plasma Sci. 24, 1188-1191 (1996).

${ }^{5}$ S. Förster, C. Mohr, and W. Viöl, Surf. Coat. Technol. 200, 827-830 (2005).

${ }^{6}$ J. L. Walsh, J. J. Shi, and M. G. Kong, Appl. Phys. Lett. 88, 171501 (2006).

${ }^{7}$ Z. Cao, Q. Nie, and M. Kong, J. Phys. D: Appl. Phys. 42, 222003 (2009).

${ }^{8}$ D. B. Kim, S. Y. Moon, H. Jung, B. Gweon, and W. Choe, Phys. Plasmas 17, 053508 (2010).

${ }^{9}$ Y. T. Zhang, Q. Q. Li, J. Lou, and Q. M. Li, Appl. Phys. Lett. 97, 141504 (2010).

${ }^{10}$ J. H. Liu, X. Y. Liu, K. Hu, D. W. Liu, X. P. Lu, F. Iza, and M. G. Kong, Appl. Phys. Lett. 98, 151502 (2011).

${ }^{11}$ D. Bayliss, J. Walsh, G. Shama, F. Iza, and M. Kong, New J. Phys. 11, 115024 (2009).

${ }^{12}$ G. A. Dawson and W. P. Winn, Z. Phys. 183, 159-171 (1965).

${ }^{13}$ Q. Xiong, X. P. Lu, K. Ostrikov, Y. Xian, C. Zou, Z. Xiong, and Y. Pan, Phys. Plasmas 17, 043506 (2010).

${ }^{14}$ X. Lu and M. Laroussi, J. Appl. Phys. 100, 063302 (2006).

${ }^{15}$ J. L. Walsh, F. Iza, N. B. Janson, V. J. Law, and M. G. Kong, J. Phys. D: Appl. Phys. 43, 075201 (2010).

${ }^{16}$ Y. P. Raizer, Gas Discharge Physics (Springer, 1991).

${ }^{17}$ D. W. Liu, F. Iza, and M. G. Kong, Appl. Phys. Lett. 95, 031501 (2009).

${ }^{18}$ D. W. Liu, J. J. Shi, and M. G. Kong, Appl. Phys. Lett. 90, 041502 (2007).

${ }^{19}$ E. Karakas and M. Laroussi, J. Appl. Phys. 108, 063305 (2010).

${ }^{20}$ I. Gallimberti, J. Phys. D: Appl. Phys. 5, 2179-2189 (1972).

${ }^{21}$ G. V. Naidis, Appl. Phys. Lett. 98, 141501 (2011).

${ }^{22}$ D. Liu, M. Rong, X. Wang, F. Iza, M. Kong, and P. Bruggeman, Plasma Processes Polym. 7, 846-865 (2010). 